\title{
Watering Strategy, Collective Action, and Neighborhood-Planted Trees: A Case Study of Indianapolis, Indiana, U.S.
}

\author{
Sarah K. Mincey and Jessica M. Vogt
}

\begin{abstract}
A growing number of municipalities and nonprofits work with private citizens to co-produce the public benefits associated with urban forests by providing sizeable young trees to neighborhoods that agree to plant and water the trees for the critical first few years after planting. Little research has addressed the effectiveness of such programs or the extent to which variation in neighborhood maintenance and watering strategies may be related to biophysical and social outcomes. Without such knowledge, tree-planting investments are at risk of being a sink of public or charitable funds. This paper presents a case study of Keep Indianapolis Beautiful, Inc.s neighborhood tree plantings in Indianapolis, Indiana, U.S., where researchers explored the relationship of neighborhood watering strategies with planted-tree outcomes, and with subsequent collective activities. The study authors observed neighborhood variation in whether trees were watered by individuals or collectively (groups of individuals), whether signed watering commitments were utilized, whether monitoring of watering occurred, and whether monitoring and subsequent sanctioning (when necessary) changed watering behavior. Results demonstrate that collective watering, signed watering agreements, and monitoring/sanctioning that changed behavior were positively associated with tree survival. Collective watering was also positively associated with subsequent collective activities, such as a neighborhood clean-up or block party. Such findings can improve the guidance offered by municipalities and nonprofits to neighborhoods for the management of successful tree-planting projects, and can ultimately improve the survival, growth, and thereby benefits provided by neighborhood-planted trees.

Key Words. Collective Action; Indiana; Indianapolis; Institutions; Planting; Tree-planting Programs; Urban Forest Management; Watering.
\end{abstract}

Urban forests provide myriad ecosystem services that constitute public goods. Municipalities and nonprofits interested in the provision of public benefits are increasingly engaged in a variety of tree conservation and planting strategies. In fact, recent research finds that 127 (40\%) of 329 sampled U.S. cities with populations over 50,000 have adopted an urban tree canopy cover goal, and 246 (74.7\%) have adopted a tree ordinance specifying tree-planting requirements for developers (Krause 2011). Less is known about the number of nonprofits engaged in tree conservation and planting strategies. Approximately 200 organizations are members of Alliance for Community Trees (ACTrees), a U.S.-based organization that supports grassroots, citizen-based nonprofit organizations dedicated to urban and community tree planting and care (ACTrees 2012). Many of ACTrees' member organizations serve a dual mission to improve the provision of urban trees and to engage their communities by empowering people in collective efforts for public good. ACTrees organizations work primarily through community groups (e.g., churches, civic organizations) and neighborhood associations comprising individual citizens. To this end, some provide free or reducedcost trees to groups that apply and have developed a plan to water young trees after planting; after all, it costs approximately USD $\$ 150$ to plant a street tree, while both planting and providing two years of maintenance costs approximately $\$ 250$ (ACTrees 2012). With watering maintenance (and its costs) pledged by community group applicants, treeplanting organizations cover tree stock and planting expenses through donated funds, partnerships with municipalities, or through cost-share agreements with groups receiving trees. Thus, nonprofits work synergistically with these community groups to coproduce (cooperatively manage through planting and watering) the urban forest, relying on these groups to internally fulfill their watering commitments. 
Despite these efforts and a group's best-laid plans, unwatered trees may fail to survive in harsh urban environments and become a sink of public or charitable funds instead of being a source of public goods (e.g., the benefits of trees) (Appleyard 2000). The potentially high transaction costs (e.g., informationgathering, negotiating, and enforcement tasks) associated with a community group's efforts to internally manage their members' contributions to their collective watering commitment make this outcome a real possibility, yet little research exists to define the magnitude of this problem. Moreover, little is known about the variety of strategies used by participating community groups to ensure maintenance of newly planted trees or their relative success or failure as defined by the general mission of tree-planting organizationsthe survival and thus provision of urban trees and the empowerment of people in collective efforts for public good. Such information could greatly enhance nonprofits' efforts (and by extension, municipalities' efforts) in supporting successful urban tree-planting projects and the co-production of public goods.

This paper addresses the dearth of information regarding neighborhood-planted tree management through a case study of Indianapolis, Indianas Keep Indianapolis Beautiful, Inc. (KIB) and their NeighborWoods tree-planting program. Specifically, researchers examine the variety of tree-watering plans across Indianapolis neighborhoods (a specific type of community group) and ask: How does tree survival, condition, and growth vary by neighborhood watering strategy and to what extent is watering strategy related to neighborhood collective action? The authors recognize that, in this single case, study generalizable evidence of causal relationships cannot be provided. However, in using a combination of qualitative interview data and theory from rural, collective natural resource management settings, a better understanding of the nature of relationships between outcomes of neighborhood-initiated tree planting, watering strategies, and collective action can be discerned, providing a foundation for future research in this area.

\section{THEORETICAL BACKGROUND}

\section{Using the Vocabulary of Institutional Theory and Collective Action}

Conversations with urban forestry nonprofits have led us to conclude that these organizations are often very much aware that they are operating in socialecological systems of both trees and people. However, they often struggle to find a language to describe the types of social change their tree-planting activities aim to inspire. KIB defines their vision as "a vibrant city, with every neighborhood landscape thriving and well, and its people empowered, mobilized, and devoted toward that vision" (KIB 2009). The study authors believe the vocabulary of collectiveaction literature is synonymous but arguably contains more efficient and effective language for the vision of such tree-planting organizations. It is also the belief of the authors that extending the application of institutional theories of collective action to the fields of urban forestry and urban ecology is a crucial step toward understanding urban neighborhoods in the context of sustainability (Mincey et al. 2013). In the remainder of this section, these social and institutional theories related to collective action and co-production of resources are reviewed.

\section{Collective Action and Co-production}

Collective action is an important concept in understanding the co-production of urban services (Ostrom 1996; Ostrom 2009; Adger 2003; Marschall 2004). While varying definitions exist within the literature, most definitions of collective action involve a group of people with some shared interest whose realization depends upon the coordinated actions of that group (Meinzen-Dick et al. 2004). Co-production is a process by which citizens participate in the collective provision of local public goods in order "to communicate preferences and influence policymaking .... to assist in the implementation of the public good and to contribute to its preservation and continuation" (Marschall 2004, p. 232), and is, therefore, a form of collective action. Studies by Ostrom and colleagues in the 1960s on urban policing demonstrated that citizen involvement in the provision of policing services (a form of co-production of these services) yielded enhanced service delivery (Ostrom et al. 1973). Additionally, Marschall (2004) found that citizen participation in the co-production of public safety and schooling efforts was related to citizen involvement in both formal and informal associations (or other forms of collective action). While not directly related to tree growth or survival, this literature suggests that the engagement of neighborhoods or other civic groups in the co-production 
of tree planting and management may enhance the success of tree-planting projects (i.e., higher tree survival rates), and may be associated with citizen involvement in other forms of collective action or citizen groups, such as neighborhood associations.

\section{Collective Action and Institutions}

Successful collective action depends largely upon institutions-the rules, norms, or strategies that groups use to structure repeated behavior (Ostrom 2005). Without institutions, collective action is relatively costly for individuals in terms of the time and effort required to come to agreement and to engage in mutually agreed-upon actions. Institutional mechanisms change the costs and benefits for individuals facing collective action problems, such as free riding (where individuals "cheat," consuming more than or paying less than their fair share of a common resource). Institutions can be used to impose sanctions on free riders such that the costs of cheating outweigh the perceived benefits (Ostrom 2005).

A number of institutional mechanisms have been associated with sustainable outcomes in collective natural resource management and were specified in the Design Principles (Ostrom 1990; Cox et al. 2010). These institutional characteristics were found in various forms and combinations among sustainable resource communities (including fisheries, forests, and irrigation systems) studied by Ostrom (1990). For example, the Design Principles point to the relevance of locally defined rules, the clarity of resource boundaries and responsibilities, and effective monitoring and sanctioning for sustainable collective natural resource management. Ostrom (1990) concluded that when individuals working together are able to establish such institutions about shared responsibilities and have means to monitor and sanction those that fail to conform to rules, they are more accountable to one another and accomplish more than individuals who do not (Ostrom et al. 1994). While not yet applied to urban forest management, these principles have emerged in recent studies related to urban vegetation management; for example, Robbins and Sharpe (2003) report that upholding local aesthetic norms and the fear of neighborhood sanctions are key drivers to individual households' front yard maintenance that produce collective (neighborhood) results. Thus, given the Design Principles and related evidence, it is expected that neighborhoods that engage in collective tree-planting and maintenance activities (a form of collective natural resource management) and establish rules, monitoring, and sanctioning related to those shared responsibilities will be more accountable to one another and therefore may produce more successful tree-planting projects.

\section{Collective Action and Social Capital}

Successful collective action through institutional conformance has been linked to the existence of social capital both within and across groups (Ostrom 1996; Putnam 2000; Adger 2003). Putnam (2000, p. 19) discusses "social capital" and defines it as it was used in the present study: "social networks and the norms of reciprocity and trustworthiness that arise from them." Social capital is related to collective action because "social capital allows citizens to resolve collective problems more easily," because "where people are trusting and trustworthy, and where they are subject to repeated interactions with fellow citizens, everyday business and social transactions are less costly" (Putnam 2000, p. 288). Further, Poteete et al. (2010, pp. 226-227) link trust and institutional conformance: "At the core of an evolving theoretical explanation of successful . . collective action is the internal link between the trust among participants ... and the increased probability that all participants will use reciprocity norms"; "trust and reciprocity are mutually reinforcing."

Sociologists debate the conflation of social capital with individual-level capital; and like Putnam (2000), researchers of the current study acknowledge that social capital is related to the idea of civic virtue-the individual-level construct of altruism or action for the general welfare of society. Putnam (2000, p. 19) states, "civic virtue is most powerful when embedded in a dense network of reciprocal social relations," but that "a society of many virtues but isolated individuals is not necessarily rich in social capital"; nor, therefore, collective action. Given the nature of the study's focus-neighborhood-managed tree planting and management requiring collective decision making and institutional design-the concept of social capital and its role in institutional conformance for successful collective action is appropriate.

No systematic, quantitative research has been done to evaluate urban tree-planting programs from a social outcomes perspective other than Sommer 
et al.s (1994) analysis of individual-level satisfaction and engagement in tree planting. Elmendorf (2008) cites an extensive literature from urban planning and community development research, outlining the theoretical linkages between trees, tree planting, and community capacity and development; yet, to the knowledge of the authors, no research has empirically analyzed the effects of tree-planting programs on neighborhood collective action. However, the existing literature indicates reason to suspect that participation in collective tree-planting and management activities may have positive effects on other types of collective engagement. Consequently, the authors expect neighborhoods that engage in collective tree-planting and management activities will build social capital (or social networks and the reinforcing norms of reciprocity and trustworthiness that arise from them) and are thus likely to engage in additional collective efforts.

Ultimately, collective action, co-production, institutions, and social capital in neighborhoodinitiated tree plantings should theoretically lead to more consistent and frequent efforts to maintain (water) trees. Long-term water stress can decrease both root and shoot growth rates (Kozlowski and Pallardy 1997), and because tree establishment depends on root growth (Nilsson et al. 2008), trees facing sufficient constraints to establishment through lack of water will not survive or grow in the landscape (Appleyard 2000). Thus, growth and/ or survival are potentially impacted by irrigation practices in urban settings. Because of the known importance of watering to planted tree survival and growth (e.g., Whitlow et al. 1992; Kozlowski and Pallardy 1997; Appleyard 2000; Gilman 2004), the authors expect any neighborhood activities that lead to frequent and consistent watering throughout the first few seasons after planting to be related to higher tree survival, condition, and/or growth rates.

\section{METHODS}

\section{Study Site}

To examine if tree survival, condition, or growth varies between tree-watering strategies and to what extent a strategy may influence neighborhood collective action, researchers partnered with KIB to study a sample of neighborhoods throughout Indianapolis and Marion County, Indiana, that have participated in the organization's NeighborWoods program. Founded in 1976, KIB is a 501c(3), private, not-for-profit organization, and an award-winning affiliate of ACTrees. KIB's NeighborWoods program, begun in 2006 as part of the larger ACTrees NeighborWoods initiative, is an urban forestry effort to strategically plant 100,000 trees throughout the City of Indianapolis and Marion County (under a single metropolitan government unit). Indianapolis is the state capital, with a growing population of just over 800,000 (U.S. Census 2010). The total area of the consolidated metropolis is approximately $966 \mathrm{~km}^{2}$ and is located in a flat, glaciated plain.

KIB NeighborWoods requires submission of an application demonstrating a group's self-organized plan to aid in the planting and establishment of $\sim 2.5-5 \mathrm{~cm}$ caliper trees through a structured watering strategy of the neighborhood's choosing. Strategies generally fall along a continuum from "collective watering," in which neighbors gather at a specified time to water all trees, to "individual watering," in which individual neighbors are responsible for one or more trees (usually near their home) and water them individually at any time. Regardless of the specific type of watering strategy chosen, neighborhoods are instructed to give each planted tree at least 56.8 $\mathrm{L}$ of water every week during the summer (AprilOctober) during which it does not rain at least $2.5 \mathrm{~cm}$.

The study authors selected a stratified sample of neighborhoods and homeowners associations (subsequently referred to as "neighborhoods") throughout Indianapolis that participated in KIB's NeighborWoods program between 2006 and 2009, based on a KIB list of projects by watering strategy. Watering strategies were dichotomized and project selection was based on balancing the sample between the two types: 1) neighborhoods where there was some form of collective watering, and 2) neighborhoods in which only individual watering was conducted. Thirty-six projects in 25 distinct neighborhoods were identified and selected in which a minimum of $\sim 20$ trees were planted, and for purposes of access, where trees were planted in or near the public right-of-way or in common areas.

\section{Social Data Collection}

Upon project selection, KIB employees provided contact information for at least one individual from each neighborhood who was involved in help- 
ing manage one or more of the tree-planting projects in that neighborhood. Because the same individual generally managed multiple projects within a neighborhood, in the analyses, all tree-planting projects in a single neighborhood were considered part of the same sampling unit. In the summers of 2011 and 2012, these individuals were contacted for an interview at a location of the interviewee's choosing in Indianapolis. (In two cases, interviews were conducted over the phone as the individuals had moved away from the study site.) Of the 25 neighborhoods for which interview requests were made, a total of 18 neighborhoods were represented through 18 interviews with one to four individual residents in attendance for each. The contacts for seven neighborhoods could not be reached.

In the summer of 2011, two interviewers (one lead, one notetaker) were present for interviews, which were not audio recorded $(n=6)$. In the summer of 2012, audio recording was approved by the researchers' institutional review board; subsequently, one interviewer was present for each interview, which was recorded and later transcribed ( $\mathrm{n}$ $=12$ ). In all cases, interviews were approximately one hour in length. They were semi-structured, and interviewers used a pre-determined list of interview questions to guide discussion of neighborhood characteristics, the details of the treeplanting event and subsequent watering, and other neighborhood collective activities. (A complete list of interview questions is available from the authors upon request.) Detailed interview notes and transcriptions were used to code the presence/ absence of collective watering (1/0), whether the neighborhood formalized the agreement that neighbors water through a signed commitment $(1 / 0)$, whether neighbors monitored and/or "sanctioned" (e.g., reminded, prodded) one another to water $(1 / 0)$, and whether this monitoring/sanctioning purportedly changed watering behavior $(1 / 0)$.

Additionally, to consider the potential effects of watering strategy on collective action, researchers asked interviewees to enumerate and describe collective efforts that took place in their respective neighborhoods, both before and after their initial NeighborWoods project. Although this question was open-ended, the example of a neighborhood crime watch, to help define "collective efforts," was offered. A complete list of such activities (e.g., neighborhood block parties, clean-ups, beautification efforts) was generated a posteriori and coded with $1 \mathrm{~s}$ and 0 s (presence/absence) for each neighborhood. The percentage of all potential collective activities occurring in each neighborhood before and after tree planting were generated, and an index of "change in collective activities" was created by subtracting the percent of activities after planting from the percent of activities prior to planting for each neighborhood. This yielded a metric of change in collective activities after planting.

\section{Biophysical Data Collection}

Data about the survival, growth, and condition of individual trees in each neighborhood project were collected using the Planted Tree Re-Inventory Protocol (hereafter Protocol) developed by the authors for the purpose of the study (Vogt et al. 2012; Vogt et al. 2013). Tree inventory methods were modified from those of the Urban Forestry Data Standards initiative (IUFRO et al. 2010) for use with young, recently planted trees and for use by high schoolaged youth. The authors and trained members of KIB's Youth Tree Team collected data during JuneAugust of 2011 and 2012, identifying all dead or missing trees from the total planted per project, and systematically sampling 20-30 live trees per project. For these sampled live trees, the full suite of variables in the Protocol (Vogt et al. 2013) was collected. Data collected via the Protocol were combined with information collected by KIB at the time of planting (namely, the location and number of trees planted per neighborhood, and caliper-at-planting as per time-of-sale nursery records maintained by KIB). Neighborhood-level survival rates were calculated as the percent of planted trees surviving at the time of re-inventory. Annual caliper growth rate was calculated for each sampled tree by subtracting the caliper-at-planting from the caliper measured during re-inventory (diameter at $15 \mathrm{~cm}$ above first lateral root) and dividing by the number of years (converted from the number of days) between planting and re-inventory dates. For living trees, condition was visually assessed by observers according to descriptions of "Good," "Fair," and "Poor" ratings that were used by the authors in tree inventories in Bloomington and Indianapolis, Indiana, and described in the Protocol (Vogt et al. 2013). The analyses in this paper focus on the tree survival rates, growth 
rates, and condition ratings in neighborhoods with different tree maintenance characteristics.

\section{Statistical Analysis}

Most statistical analyses were performed using the individual tree as the unit of analysis with different types of neighborhoods serving to divide the trees into categories for comparison of growth, condition, and survival rates. This allowed researchers to take advantage of the relatively large sample of trees ( $n=1,462$ trees), instead of deferring to the smaller sample of neighborhoods $(n=18)$. Analyses of collective action pre- and post-planting were conducted at the neighborhood scale. All statistical analyses were performed with Statistical Analysis Software (SAS Institute, Cary, South Carolina, U.S.). A $\chi^{2}$ test was used to test for significant differences in mortality rates (assignment to "Dead" or "Alive" category) and tree condition ratings (for Alive trees) across neighborhoods with different characteristics. T-tests and an ANOVA (for balanced samples) and a generalized linear model (for unbalanced samples) were used to test for significant differences in average growth rates between trees in neighborhoods with different characteristics (e.g., signed commitment to watering or no signed commitment). For all analyses, a $P$-value of less than 0.05 was considered statistically significant.

\section{RESULTS AND DISCUSSION}

Of the 6,366 trees planted in NeighborWoods projects by KIB between 2006 and 2009, 1,462 trees had been planted in the sampled neighborhoods; 1,304 (89\%) of them were found to be alive, while 158 (11\%) were found to be dead or missing upon sampling. Of the 1,304 living trees, growth rates were measured for 663 sample trees. Overall, average caliper growth rate was $1.11 \mathrm{~cm}$ per year (standard deviation $=0.61$ ). Of the sampled living trees, $85.4 \%$ were observed to be in good condition, while $11.2 \%$ were in fair condition, and only $2.5 \%$ were in poor condition $(0.9 \%$ of living trees were in shrub form and condition was not assessed).

\section{Watering Strategy and Signed Water- ing Agreements}

The results suggest the potential importance of watering strategies to the survival and growth of neighborhood-planted trees. The findings demon- strate that trees in neighborhoods with some collective watering were significantly more likely to be alive ( $\mathrm{n}=554,93.7 \%$ alive) than trees in neighborhoods with no collective watering $(\mathrm{n}=908$, $86.5 \%$ alive) (Table 1). Although the magnitude of observed effects is small and researchers cannot make a causal claim about the mechanism through which survival and watering strategy are related given the lack of quantitative data on the consistency of tree watering by neighborhood, this finding suggests that some tree-relevant differences exist in watering strategies between neighborhoods.

There is theoretical and empirical reason to consider that collective watering increases individual accountability to follow through with planned watering, given the physical presence of other neighbors at the specified watering time, a factor that could lead to more consistent watering and thus greater tree survival. The fact that neighbors can see one another watering may lead to the perception that one could be "caught cheating" (not watering) and face social sanctioning unless one is watering per the collective agreement (an institutional mechanism). Consequently, watering in these neighborhoods may be motivated by the neighborhood social network and the norms of reciprocity (an institutional mechanism) and trustworthiness that can arise from them. While qualitative in nature and limited in number, interviewee statements in collective watering neighborhoods empirically support this reasoning; for example, "[when] the dedicated few [are watering] ...the others, out of guilt, will walk outside and start helping ... [or] come back later." For this neighborhood, and perhaps others in the sample, the collective watering strategy appears to be related to institutional conformance, which leads to consistency and frequency of tree-watering activities and thereby to tree survival.

Although surviving, the living trees in neighborhoods where at least some collective watering occurred were often in worse overall condition (Table 1) than those in neighborhoods without collective watering. The authors speculate the higher rates of tree mortality in neighborhoods without collective watering resulted in better average tree condition, possibly because the trees in the poorest condition died and dropped out of the sample of living trees given condition ratings. Gilman (2004) found similar results from analysis of 210 trees in an experimental study; the only three trees that died 
were those infrequently watered. In other words, in collective watering neighborhoods, trees in the worst conditions can "hang on" because collective watering may be more consistent, allowing them to survive in poor condition. In contrast to tree mortality rates and condition, tree growth rates did not differ significantly by neighborhood watering strategy, although the mean growth rate was higher for neighborhoods with some collective watering (Table 1).

Compared to trees in neighborhoods without signed watering agreements, trees in neighborhoods with signed watering agreements had significantly higher growth rates, but not survival rates or condition ratings; on average, both survival rates and condition ratings were higher for trees in neighborhoods with signed watering agreements (Table 2). These results suggest the importance of signed agreements as a formal (written) institution for ensuring tree success and establishing accountability to neighbors and perhaps also to KIB. Other studies have emphasized the importance of written rules for building social capital and influencing natural resource outcomes. Svendson and Svendson (2010) attribute the written form of cooperative farming association rules in Denmark to the growth of voluntary networks that represent beneficial social capital building that led to economic growth in poor rural areas. Alternatively, results of the current study may simply suggest that there is something different (in terms of growing conditions for street trees) about neighborhoods that choose to make a signed commitment to maintaining planted trees than those neighborhoods that do not make this commitment.

Table 1. Survival rates, tree condition ratings, and annual caliper growth for trees in sampled KIB NeighborWoods projects with different watering strategies.

\begin{tabular}{|c|c|c|c|}
\hline \# of neighborhoods & & $\begin{array}{l}\text { No collective (individual) } \\
\text { watering } \\
8\end{array}$ & $\begin{array}{l}\text { Some collective } \\
\text { watering } \\
10\end{array}$ \\
\hline Survival $^{\mathrm{z}}$ & $\begin{array}{l}\text { Alive } \\
\text { Dead } \\
\text { Total n }\end{array}$ & $\begin{array}{l}86.5 \% \\
13.5 \% \\
908\end{array}$ & $\begin{array}{l}93.7 \% \\
6.3 \% \\
554\end{array}$ \\
\hline $\begin{array}{l}\text { Tree condition } \\
\text { rating }\end{array}$ & $\begin{array}{l}\text { Good } \\
\text { Fair } \\
\text { Poor } \\
\text { Total n }\end{array}$ & $\begin{array}{l}88.3 \% \\
9.5 \% \\
2.2 \% \\
358\end{array}$ & $\begin{array}{l}81.2 \% \\
15.4 \% \\
3.4 \% \\
298\end{array}$ \\
\hline $\begin{array}{l}\text { Annual caliper } \\
\text { growth }^{x}\end{array}$ & $\begin{array}{l}\text { Mean } \\
\text { Std. dev. } \\
\text { Total n }\end{array}$ & $\begin{array}{l}1.11 \mathrm{~cm} / \mathrm{yr} \\
0.62 \mathrm{~cm} / \mathrm{yr} \\
357\end{array}$ & $\begin{array}{l}1.15 \mathrm{~cm} / \mathrm{yr} \\
0.61 \mathrm{~cm} / \mathrm{yr} \\
302\end{array}$ \\
\hline
\end{tabular}

${ }^{2}$ Significant differences: $\chi^{2}: \mathrm{n}=1462, \chi^{2}=18.652, P<0.0001$.

y Significant differences: $\chi^{2}: \mathrm{n}=656, \chi^{2}=6.402, P=0.041$.

${ }^{\mathrm{x}}$ No significant differences: $\mathrm{t}$-test: $\mathrm{n}=659, \mathrm{t}=-0.83, P=0.409$.

Note: Percentages may not add up to $100 \%$ due to rounding error. Analyses were performed for trees in neighborhoods with interview data.

Table 2. Survival rates, tree condition ratings, and annual caliper growth for trees in sampled KIB NeighborWoods projects with and without signed watering agreements.

\begin{tabular}{llll}
\hline & & No signed agreement & Signed agreement \\
\# of neighborhoods & & 11 & 7 \\
\hline Survival $^{z}$ & Alive & $88.3 \%$ & $91.5 \%$ \\
& Dead & $11.8 \%$ & 375 \\
& Total n & 698 & 375 \\
& & & $85.0 \%$ \\
Tree condition & Good & $83.7 \%$ & $12.9 \%$ \\
rating & Fair & $12.9 \%$ & $2.2 \%$ \\
& Poor & $3.5 \%$ & 186 \\
& Total n & 319 & $1.27 \mathrm{~cm} / \mathrm{yr}$ \\
Annual caliper & Mean & $1.04 \mathrm{~cm} / \mathrm{yr}$ & $0.62 \mathrm{~cm} / \mathrm{yr}$ \\
growth $^{\mathrm{x}}$ & Std. dev. & $0.55 \mathrm{~cm} / \mathrm{yr}$ & 191 \\
& Total n & 317 & \\
\hline
\end{tabular}

${ }^{2}$ No significant differences: $\chi^{2}: \mathrm{n}=1073, \chi^{2}=2.655, P=0.103$

y No significant differences: $\chi^{2}: \mathrm{n}=505, \chi^{2}=0.688, P=0.709$

${ }^{x}$ Significant differences: GLM: $\mathrm{n}=508, \mathrm{~F}=18.68, P<0.0001$.

Note: Percentages may not add up to $100 \%$ due to rounding error. Analyses were performed for trees in neighborhoods with interview data. 


\section{Monitoring and Sanctioning}

Monitoring is positively related to tree survival (Table 3 ), while monitoring and sanctioning that reportedly changed watering behavior appear to have had a positive impact on both survival and growth (Table 4). These findings support Ostrom's Design Principles regarding monitoring and sanctioning (Ostrom 1990; Cox et al. 2010). Trees in neighborhoods that monitored whether trees were watered were significantly more likely to be alive than trees in neighborhoods with no monitoring. However, monitoring alone appears to have no influence on tree growth or overall tree condition (Table 3). Monitoring occurs naturally in collective watering scenarios because individuals in the group can generally see one another watering. However, many interviewees referred explicitly to monitoring outside of watering times, while driving or walking in their respective neighborhoods. Parallels can be drawn from rural community forestry research; better forest conditions have been associated with the use of monitors who are local resource users themselves (Banana and Gombya-Ssembajjwe 2000; Ostrom 2005).

Monitoring alone and unknown to neighbors could have little impact if not for subsequent sanctioning (when necessary) that effectively changes behavior. Trees in neighborhoods that reported that monitoring and sanctioning increased watering were significantly more likely to be alive and experienced higher tree growth rates than trees in neighborhoods in which monitoring and sanctioning reportedly did not lead to more watering (Table 4). Monitoring and sanctioning activities that change behavior also appear to affect tree condition in the same way that collec- tive watering strategies do: trees in neighborhoods where monitoring and sanctioning affects behavior are more likely to be in poorer condition than trees in neighborhoods where monitoring and sanctioning does not change behavior (Table 4). Again, researchers speculate the higher rates of tree mortality resulted in better average tree condition, possibly because the trees in the poorest condition died and dropped out of the sample of living trees given condition ratings.

Interviewees generally reported mild sanctioning, which included confronting and prodding neighbors who were not watering or leaving reminder notes on doors, and it appears to have been effective. Mild sanctions such as these are likely the only recourse neighbors would have against those not following the informal watering rules. For instance, one interviewee stated, "So as long as people aren't afraid to call their neighbor on it, and say, 'come help me', it all works." In such a situation, the cost of mild social sanctions (i.e., the external pressure on individuals to comply with rules) likely outweighs the costs of time and energy to water, leading to greater compliance with informal watering rules. These findings that informal monitoring and mild social sanctioning improve biophysical outcomes are consistent with findings of institutional researchers in other resource systems, including those related to Ostrom's Design Principles. For instance, Gibson et al. (2005) examined 178 rural, forested communities and found that regardless of the formality of an organization, regular monitoring and sanctioning of whatever rules were actually in place related to better forest conditions, and that irregular monitoring and sanctioning of rules were associated with poorer forest conditions.

Table 3. Survival rates, tree condition ratings, and annual caliper growth for trees in sampled KIB NeighborWoods projects with and without monitoring.

\begin{tabular}{|c|c|c|c|}
\hline \# of neighborhoods & & $\begin{array}{l}\text { No monitoring } \\
\text { activities reported } \\
2\end{array}$ & $\begin{array}{l}\text { Monitoring activities } \\
\text { reported } \\
16\end{array}$ \\
\hline Survival $^{z}$ & $\begin{array}{l}\text { Alive } \\
\text { Dead } \\
\text { Total } \mathrm{n}\end{array}$ & $\begin{array}{l}73.0 \% \\
27.0 \% \\
111\end{array}$ & $\begin{array}{l}91.3 \% \\
8.7 \% \\
962\end{array}$ \\
\hline $\begin{array}{l}\text { Tree condition } \\
\text { rating }\end{array}$ & $\begin{array}{l}\text { Good } \\
\text { Fair } \\
\text { Poor } \\
\text { Total n }\end{array}$ & $\begin{array}{l}90.4 \% \\
7.7 \% \\
1.9 \% \\
52\end{array}$ & $\begin{array}{l}83.4 \% \\
13.5 \% \\
3.1 \% \\
453\end{array}$ \\
\hline $\begin{array}{l}\text { Annual caliper } \\
\text { growth }^{x}\end{array}$ & $\begin{array}{l}\text { Mean } \\
\text { Std. dev. } \\
\text { Total } \mathrm{n}\end{array}$ & $\begin{array}{l}1.12 \mathrm{~cm} / \mathrm{yr} \\
0.55 \mathrm{~cm} / \mathrm{yr} \\
51\end{array}$ & $\begin{array}{l}1.13 \mathrm{~cm} / \mathrm{yr} \\
0.59 \mathrm{~cm} / \mathrm{yr} \\
457\end{array}$ \\
\hline
\end{tabular}

Significant differences: $\chi^{2}: \mathrm{n}=1073, \chi^{2}=35.079, P<0.0001$.

'No significant differences: $\chi^{2}: \mathrm{n}=505, \chi^{2}=1.689, P=0.430$.

${ }^{\mathrm{x}}$ No significant differences: GLM: $\mathrm{n}=508, \mathrm{~F}=0.01, P=0.937$.

Note: Percentages may not add up to $100 \%$ due to rounding error. Analyses were performed for trees in neighborhoods with interview data. 
Table 4. Survival rates, tree condition ratings, and annual caliper growth for trees in sampled KIB NeighborWoods projects by whether monitoring and sanctioning changed watering behavior.

\begin{tabular}{|c|c|c|c|}
\hline \# of neighborhoods & & $\begin{array}{l}\text { Monitoring and sanctioning } \\
\text { did not change behavior } \\
8\end{array}$ & $\begin{array}{l}\text { Monitoring and sanctioning } \\
\text { changed behavior } \\
5\end{array}$ \\
\hline Survival $^{\mathrm{z}}$ & $\begin{array}{l}\text { Alive } \\
\text { Dead } \\
\text { Total } n\end{array}$ & $\begin{array}{l}89.2 \% \\
10.8 \% \\
472\end{array}$ & $\begin{array}{l}93.5 \% \\
6.5 \% \\
429\end{array}$ \\
\hline $\begin{array}{l}\text { Tree condition } \\
\text { rating }^{\mathrm{y}}\end{array}$ & $\begin{array}{l}\text { Good } \\
\text { Fair } \\
\text { Poor } \\
\text { Total n }\end{array}$ & $\begin{array}{l}88.7 \% \\
8.5 \% \\
2.8 \% \\
177\end{array}$ & $\begin{array}{l}76.4 \% \\
19.7 \% \\
3.9 \% \\
208\end{array}$ \\
\hline $\begin{array}{l}\text { Annual caliper } \\
\text { growth }^{x}\end{array}$ & $\begin{array}{l}\text { Mean } \\
\text { Std. dev. } \\
\text { Total n }\end{array}$ & $\begin{array}{l}1.00 \mathrm{~cm} / \mathrm{yr} \\
0.58 \mathrm{~cm} / \mathrm{yr} \\
176\end{array}$ & $\begin{array}{l}1.27 \mathrm{~cm} / \mathrm{yr} \\
0.59 \mathrm{~cm} / \mathrm{yr} \\
209\end{array}$ \\
\hline
\end{tabular}

${ }^{\mathrm{z}}$ Significant differences: $\chi^{2}: \mathrm{n}=901 ; \chi^{2}=5.142, P=0.023$.

y Significant differences: $\chi^{2}: \mathrm{n}=385, \chi^{2}=10.347, P=0.0057$.

'Significant differences: $\mathrm{t}$-test: $\mathrm{n}=385, \mathrm{t}=-4.47, P<0.0001$.

Note: Percentages may not add up to $100 \%$ due to rounding error. Analyses were performed for trees in neighborhoods that reported monitoring activities occurring.

\section{Collective Action}

Watering strategy may play an important role in bringing neighborhoods together for subsequent collective action. Neighborhoods that chose to water trees collectively had apparently lower levels of collective activities before their tree planting compared to neighborhoods that watered individually ( $\mathrm{t}$-test: $\mathrm{n}=18, \mathrm{t}=2.08, P=0.0541$ ), suggesting inexperience in working together upon tree planting. After their tree-planting and management projects, neighborhoods that watered at least some trees collectively experienced a positive change in collective action (i.e., significantly more collective activities, including neighborhood clean-up, block parties, and additional tree plantings), while neighborhoods choosing individual watering actually experienced a negative change in collective action (i.e., fewer collective activities were reported) (t-test: $\mathrm{n}=18, \mathrm{t}=-3.23, P=0.0052$ ).

The fact that neighborhoods were more likely to work together after collectively watering trees compared to neighborhoods that individually watered may suggest that by watering and maintaining trees together, these groups learned from the interaction and experience, and built social capital, supporting their undertaking of additional collective efforts. This theory is reflected by the sentiment of one interviewee from a neighborhood that collectively watered: "I feel like all of this [the NeighborWoods tree-planting project] has certainly brought our neighborhood closer together. It helps with the crime watch, too, because more people know each other ... and it really all started with our first NeighborWoods project. It's been good - [a] huge success."

Working through the collective operation of watering appears to give a sense of accomplishment in the neighborhood and the feeling of accountability to one another; characteristics that one might argue demonstrate trust. Trust allows individuals to feel as though they won't be cheated or end up as the "sucker" doing all the work(Ostrom 2000); thus, additional efforts seem less costly. Another interviewee explained that more regular neighborhood board meetings resulted in "more of a community feel, and [we started to] take ownership for what was going on." Other neighborhoods echoed the sense that tree-planting project ownership could actually lead to greater ownership in the neighborhood as a whole.

Several reasonable causal pathways explain why neighborhoods that watered individually had higher levels of collective activities prior to treeplanting/watering and lower post-tree planting/ watering collective activities. It is possible that such neighborhoods could have experienced unsuccessful collective activities prior to tree planting and therefore decided to water trees individually and avoid additional collective activities. Alternatively, such neighborhoods could have built such great trust and norms of reciprocity (as previously described) via prior successful collective activities that they felt "strong" enough to avoid "cheaters" while using individual watering strategies. To tease out the relevance of each of these causal pathways requires additional research. 


\section{CONCLUSIONS AND IMPLICATIONS}

The findings here suggest the importance of watering strategies for the survival and growth of neighborhood-planted trees, as well as for building subsequent collective efforts in neighborhoods and homeowners associations. Such findings may have implications for nonprofits and the management of tree-planting projects. However, prior to considering these practical implications, it is important to recognize two important contextual issues: first, a word of caution about analyzing institutional variables in isolation of biophysical or social variables is necessary; and second, the organizational context in which these neighborhood strategies operated as observed in this study is relevant.

The authors recognize that the watering and management strategies discussed here do not occur in a vacuum: there are social and biophysical variations both between and within neighborhoods that may affect how trees survive and grow and how neighborhoods work together. Variation in socioeconomic status, such as household income, family stage/structure, and other factors may affect the ability of a neighborhood to care for trees. Differences in species composition, biophysical growing conditions, and at-planting parameters, such as nursery of origin or packaging, both within and between neighborhoods, may impact the success of individual trees. However, as many biophysical parameters are impossible to assess for dead or absent trees and water availability has been shown to be one of the most important variables influencing tree survival (Kozlowski and Pallardy 1997), it is believed that the results shown regarding watering strategy are important to consider. Researchers also recognize the possibility of multiple causal pathways and do not purport that there is necessarily a direct causal relationship between watering strategies and tree outcomes. Future research will consider the simultaneous influence of watering strategy and other neighborhood-level socioeconomic/demographic factors as they vary with tree-level biophysical parameters.

The watering and management strategies discussed here also occur within an organizational context that can influence their success. KIB has established a NeighborWoods tree-planting program that creates an excellent institutional environment for enduring and effective neighborhood tree man- agement; in fact, their practices echo the Design Principles (Ostrom 1990; Cox et al 2010). By working together to plant the trees, and KIB providing groups with the information and some means to undertake projects, KIB and neighborhoods are working as nested enterprises-sharing the burden of a complex resource management undertaking. By allowing neighborhoods to collectively choose their own watering strategies, KIB is also supporting the principle that rules should fit local environmental and social conditions. Furthermore, by offering autonomy to the neighborhoods in the management of their watering strategies, KIB, as a "higher authority," is recognizing the rights of the local people (i.e., the neighborhood) to devise their own rules, yet another of Ostrom's (1990) Design Principles. Given the average rate of tree success in NeighborWoods communities within this context (an average fiveyear tree survival rate of $89 \%$ ), it appears that KIB's program management, which unintentionally follows multiple Design Principles, is rather effective.

In keeping with these ideas, the observed variation in watering strategies between neighborhoods is not only expected but desired. Ostrom's (1990) Design Principles imply the desirability of diversity by finding that rules should fit local conditions. Additionally, tenets of adaptive management suggest the same: variation in management strategies within a resource system or between like resource systems allows for natural experimentation (of which this study has taken advantage) and bolsters robustness of the resource sector as a whole (Holling 1995). By examining trees in neighborhoods with different watering strategies, one can determine which strategies work well and which work poorly in various contexts, and avoid losing all planted trees in the worst-case scenario that a single applied strategy fails. Thus, it is important to recognize that there are no panaceas in terms of one best management strategy (Ostrom et al. 2007). While higher tree survival was found among neighborhoods that watered collectively, other strategies were observed that support tree growth, including the presence of signed watering agreements. For example, some neighborhoods may be unable to find one time to water together, but may be better equipped with other mechanisms to maintain accountability, such as utilization of social media to "check in" when individuals water. Effective strategies can be developed 
from the bottom up (neighborhoods) with support and relevant information-sharing from the top (KIB).

Thus, the study authors advocate that tree-planting nonprofits working with neighborhoods and homeowner associations share the results of this study and the relevant theory addressed herein with community groups devising their own tree management strategies. The authors conclude that for groups interested in both planted-tree survival and building social capital, collective watering strategies may be most effective. Utilization of some form of signed watering agreement may improve accountability to water and therefore tree growth. Moreover, monitoring and subsequent sanctioning, even in the form of prodding a neighbor who slacks in watering, appears to be an effective tool for improving both survival and growth of neighborhood-planted trees. These strategies, and those undertaken by nonprofits that offer autonomy and support to neighborhoods and community groups, may best set the stage for efficient co-production of urban forests.

Acknowledgements. The authors would like to thank employees of Keep Indianapolis Beautiful, Inc. for their time and data support related to this research as well as the Efroymson Family Fund for the generous grant that funded this research. The Garden Club of America's Urban Forestry Fellowship provided additional support for this project to JMV. We also appreciate the administrative support provided by the Center for the Study of Institutions, Population, and Environmental Change at Indiana University. We are thankful for the time and information provided by the numerous neighborhood representatives we interviewed regarding their experiences maintaining NeighborWoods trees. And finally, we appreciate the careful reviews of this manuscript by Graham Epstein, the journal editor, and anonymous reviewers.

\section{LITERATURE CITED}

ACTrees (Alliance for Community Trees). 2012. Alliance for Community Trees. Accessed 10/07/2012. <www.actrees.org>

Adger, W. 2003. Social capital, collective action, and adaptation to climate change. Economic Geography 79(4):387-404.

Appleyard, H.S. 2000. A strategy to establish trees among highdensity housing. Journal of Arboriculture 26(2):78-86.

Banana, A.Y., and W. Gombya-Ssembajjwe. 2000. Successful forest management: The importance of security of tenure and rule enforcement in Ugandan Forests. pp. 87-98. In: C.C. Gibson, M.A. McKean, and E. Ostrom (Eds.). People and Forests: Communities, Institutions, and Governance. The MIT Press, Cambridge, Massachusetts, U.S.

Cox, M., G. Arnold, andS. Villamayor Tomás. 2010. A review of design principles for community-based natural resource management. Ecology and Society 15(4):38. <www.ecologyandsociety.org/ vol15/iss4/art38/Elmendorf 2008>

Elmendorf, W. 2008. The importance of trees and nature in community: A review of the relative literature. Arboriculture \& Urban Forestry 24(3):152-156.
Gibson, C., J.T. Williams, and E. Ostrom. 2005. Local enforcement and better forests. World Development 33(2):273-284.

Gilman, E.F. 2004. Effects of amendments, soil additives, and irrigation on tree survival and growth. Journal of Arboriculture 30(5):301-310.

Holling, C.S. 1995. What barriers? What bridges? pp. 3-36. In: L.H. Gunderson, C.S. Holling, and S.S. Light (Eds.). Barriers and Bridges to the Renewal of Ecosystems and Institutions. Columbia University Press, New York, New York, U.S.

IUFRO (International Union of Forest Research Organizations), International Society of Arboriculture (ISA), United States Forest Service (USFS), and Urban Natural Resources Institute (UNRI). 2010. Standards for Urban Forestry Data Collection: A Field Guide, Draft 2.0. Urban Natural Resources Institute. Accessed 03/06/2013. <www.unri.org/standards/>

KIB (Keep Indianapolis Beautiful, Inc.). 2009. Keep Indianapolis Beautiful: Mission. Accessed 03/06/2013. <www.kibi.org/history_facts_and_stats>

Kozlowski, T.T., and S.G. Pallardy. 1997. Growth Control in Woody Plants. Academic Press, San Diego, California, U.S. 641 pp.

Krause, R. 2011. An assessment of the greenhouse gas reducing activities being implemented in U.S. cities. Local Environment 16(2):193-211.

Marschall, M.J. 2004. Citizen participation and the neighborhood context: A new look at the coproduction of local public goods. Political Research Quarterly 57(2):231-244.

Meinzen-Dick, R., M. Do Gregario, and N. McCarthy. 2004. Method for studying collection action in rural development. International Food Policy Research Institute. CAPRi Working Paper No. 33. Accessed 2/22/2013. <www.ifpri.org/>

Mincey, S.K., M. Hutten, B. Fischer, T. Evans, S. Stewart, and J. M. Vogt. 2013. Structuring institutional analysis for urban ecosystems: A key to sustainable urban forest management. Urban Ecosystems 16(3):553-571.

Nilsson, K., T.B. Randrup, and B.M. Wandall. 2008. Trees in the urban environment. pp. 247-236. In: J. Evans (Ed.). The Forests Handbook, Volume 1: An overview of forest science. Oxford: Blackwell Science Ltd.

Ostrom, E. 1990. Governing the Commons: The Evolution of Institutions for Collective Action. Cambridge University Press, New York, New York, U.S. 271 pp.

Ostrom, E. 1996. Crossing the great divide: Coproduction, synergy, and development. World Development 24(6):1073-1987.

Ostrom, E. 2000. Collective action and the evolution of social norms. The Journal of Economic Perspectives 14(3):137-158.

Ostrom, E. 2005. Understanding Institutional Diversity. Princeton University Press, Princeton, New Jersey, U.S. 355 pp.

Ostrom, E. 2009. A general framework for analyzing the sustainability of social-ecological systems. Science 325:419-422.

Ostrom, E., M. Janssen, and J.M. Anderies. 2007. Going beyond panaceas. Proceedings of the National Academy of Sciences of the United State of America 104(39):15176-15178.

Ostrom, E., R. Gardner, and J. Walker. 1994. Rules, Games, and Common-Pool Resources. The University of Michigan Press, Ann Arbor, Michigan, U.S. 369 pp.

Ostrom, E., R.B. Parks, and P. Whitaker Gordon. 1973. Do we really want to consolidate urban police forces? A reappraisal of some old assertions. Public Administration Review 33(5):423-432

Poteete, A., M.A. Janssen, and E. Ostrom. 2010. Working Together: Collective Action, the Commons, and Multiple Methods in 
Practice. Princeton University Press, Princeton, New Jersey, U.S. 346 pp.

Putnam, R.D. 2000. Bowling Alone: The Collapse and Revival of American Community. Simon \& Schuster, New York, New York, U.S. 544 pp.

Robbins, P., and J. Sharpe. 2003. The lawn-chemical economy and its discontent. Antipode 35(5):955-979.

Sommer, R., F. Learey, J. Summit, and M. Tirrell. 1994. The Social Benefits of Resident Involvement in Tree Planting. Journal of Arboriculture 20(3):170-175.

Svendson, G.L.H., and G.T. Svendson. 2010. The kick-starter: Entrepreneurship and social capital in the Danish Cooperative Movement. In: P. Maiti. Global and Local Polemics of Development. Concept Publishing Company Pvt. Ltd., New Delhi, India.

U.S. Census. 2010. State and County quick facts: Indianapolis, Indiana. Accessed 09/12/2012. <http://quickfacts.census.gov>

Vogt, J.M., S.K. Mincey, B.C. Fischer, and M. Patterson. 2013. Planted Tree Re-Inventory Protocol. Bloomington Urban Forest Research Group at CIPEC, Indiana University. 93 pp. <www. indiana.edu/ cipec/research/bufrg_protocol.php>

Vogt, J.M., S.K. Mincey, M. Patterson, and B.C. Fischer. 2012. Predicting urban tree success: Establishment, maintenance, growth and condition of neighborhood-initiated tree plantings. In: Proc. of Trees: A Global Necessity, International Society of Arboriculture 88th Annual Conference \& Trade Show. International Society of Arboriculture, Portland, Oregon, U.S.

Whitlow, T.H., N.L. Bassuk, and D.L. Reichert. 1992. A 3-year study of water relations of urban street trees. Journal of Applied Ecology 29(2):436-450.

Sarah K. Mincey, Ph.D. (corresponding author) Indiana University - Center for the Study of Institutions, Population, and Environmental Change and the Vincent and Elinor Ostrom Workshop in Political Theory and Policy Analysis 408 N. Indiana Ave.

Bloomington, Indiana 47408, U.S.

skmincey@indiana.edu

Jessica M. Vogt, M.P.A / M.S.E.S

Indiana University - School of Public and Environmental Affairs and the Center for the Study of Institutions, Population, and Environmental Change

408 N. Indiana Ave.

Bloomington, Indiana 47408, U.S.

jesvogt@indiana.edu
Zusammenfassung. Eine wachsende Anzahl von Stadtverwaltungen und Nicht-Profiteuren arbeiten mit privaten Bürgern, um die öffentlichen Vorteile, die mit Straßenbäumen assoziiert werden gemeinsam zu produzieren, indem junge Bäume an die Nachbarschaft geliefert werden, die sich wiederum um die Pflanzung und Bewässerung der Bäume in den ersten kritischen Jahren nach der Pflanzung kümmert. Bislang hat sich wenig Forschung um die Effektivität solcher Programme gekümmert oder zu welchem Ausmaß in der Nachbarschaft Pflege und Bewässerungsstrategien zu biophysikalischen und sozialem Auskommen in Beziehung gestellt werden können. Ohne solche Kenntnis sind Baumpflanzungsinvestments ein Risiko für öffentliche und gemeinnützige Finanzierung. Diese Studie präsentiert eine Fallstudie von: Indianapolis Beautiful, Inc., einer nachbarschaftlichen Baumpflanzungs-Initiative in Indianapolis, Indiana, U.S., wo die Forscher die Beziehung der nachbarschaftlichen Bewässerungsstrategien und das Überleben der gepflanzten Bäume mit den subsequenten kollektiven Aktivitäten untersuchten. Die Autoren dieser Studie beobachteten Variationen in der Nachbarschaft, in welcher die Bäume von Individuen oder kollektiv bewässert wurden, ob Aufzeichnungen zur Bewässerung geführt wurden und ob die Überwachung und subsequente Sanktionierung das Bewässerungsverhalten änderte. Die Resultate demonstrieren, dass kollektives Wässern, festgeschriebene Wasservereinbarungen und Monitoring/Sanktionierung, welches das Verhalten beeinflusst, positiv mit den Überleben der Bäume verbunden ist. Kollektives Wässern war auch positiv korreliert mit subsequenten kollektiven Tätigkeiten, wie allgemeines Aufräumen und Blockparties. Solche Ergebnisse können die Führung, angeboten durch Stadtverwaltung und Gemeinnützige an die Nachbarschaft, für das Management für erfolgreiche Baumpflanzprojekte und letztendlich das Überleben, Wachstum und daher auch die Vorteile, die nachbarschaftlich gepflanzte Bäume liefern, verbessern.

Resumen. Un número creciente de municipios y organizaciones no lucrativas trabajan con ciudadanos para co-producir los beneficios públicos asociados a los bosques urbanos, proporcionando árboles jóvenes a los barrios que están de acuerdo en plantarlos y regarlos durante los primeros años críticos después de la plantación. Poca investigación se ha ocupado de la eficacia de este tipo de programas o el grado en que la variación en el mantenimiento por el barrio y las estrategias de riego puede estar relacionada con los resultados biofísicos y sociales. Sin este conocimiento, las inversiones de plantación de árboles están en riesgo de ser un sumidero de fondos públicos o de caridad. En este trabajo se presenta un estudio de caso del vecindario de Keep Indianapolis Beautiful, donde los investigadores exploraron la relación entre las estrategias de riego por el barrio con los resultados de los árboles plantados y con las actividades colectivas posteriores. Los autores del estudio observaron variación en el barrio de si los árboles se regaron por individuos o colectivamente (grupos de individuos), si se utilizaron los compromisos firmados de riego, si se ha hecho el seguimiento de riego, y si el monitoreo y posterior sanción cambiaron el comportamiento de riego. Los resultados demuestran que el riego colectivo, los acuerdos firmados de riego y el seguimiento/sanción cambiaron el comportamiento y se asoció positivamente con la supervivencia del árbol. El riego colectivo también se asoció positivamente con las actividades colectivas posteriores, como una limpieza del vecindario o la fiesta del mismo. Estos hallazgos pueden mejorar la orientación ofrecida por los municipios y las organizaciones no lucrativas a los barrios sobre la gestión de proyectos exitosos de plantación de árboles, y en última instancia, puede mejorar la supervivencia, el crecimiento y de este modo los beneficios proporcionados por los árboles del vecindario que se han plantado. 